\title{
Erythrocyte Ferritin
}

\author{
F. Stanley Porter ${ }^{[17]}$ \\ Department of Pediatrics, Duke University Medical Center, Durham, North Carolina, USA
}

\begin{abstract}
Extract
Normal, human, mature erythrocytes were found to contain a protein that bound iron firmly. This protein proved to be ferritin by its physiochemical, chromatographic, electrophoretic and immunologic characteristics.

\section{Speculation}

Study of erythrocyte ferritin and its concentration and degree of iron saturation may offer insight into the availability of ferritin iron for hemoglobin synthesis as well as offer a ready method for assessment of body iron stores.
\end{abstract}

\section{Introduction}

Ferritin has been found in a variety of tissues [3], including nucleated erythroblasts and reticulocytes [2]. However, with the exception of one report [8], ferritin has not been found in mature erythrocytes. In fact, investigators have remarked on its absence and speculated on mechanisms for its removal from the maturing erythrocyte.

The present report describes experiments which demonstrate that ferritin is present in human mature erythrocytes.

\section{Methods}

\section{Chromatography}

Non-hemoglobin protein was prepared from hemolysates by chromatography on carboxymethyl cellulose at pH 6.6 with phosphate buffer in accordance with the method of Chernoff et al. [4]. Hemoglobin was retained on the column and the non-hemoglobin protein was eluted with the solvent front.

Separation of ferritin from the majority of other proteins was achieved by chromatography on carboxymethyl cellulose with acetate buffer at acid $\mathrm{pH}$ in accordance with the method of Drysdale and Munro [7].

Chromatography with Sephadex G-200 was per- formed by the method of Primosigh and Thomas [11] with $0.005 \mathrm{M}$ Tris- $\mathrm{HCl}$ buffer at $\mathrm{pH} 7.7$ with $0.01 \mathrm{M}$ EDTA.

\section{Electrophoresis}

Acrylamide gel electrophoresis was conducted by the method outlined by Nerenberg [10].

\section{Human Ferritin}

Human ferritin was prepared from spleens obtained at autopsy from patients who had been transfused recently. Ninety grams of spleen were homogenized with $200 \mathrm{ml}$ water and then centrifuged at $12,800 \times g$ for 30 min. The supernatant was chilled on ice and an equal volume of saturated ammonium sulfate was added slowly with constant stirring. The solution was refrigerated overnight and the precipitate was collected by centrifugation and washed with $50 \%$ ammonium sulfate. The precipitate was dissolved in water and dialyzed overnight at $4^{\circ}$ against $0.015 \mathrm{M}$ acetate buffer, $\mathrm{pH}$ 4.8. A heavy precipitate formed which was removed by centrifugation and the supernatant was chromatographed on carboxymethyl cellulose as described above [4]. After elution from the column, the ferritin solution was adjusted to a $\mathrm{pH}$ of 4.6 and sufficient cadmium sulfate added to make it $5 \%$ by weight. 
After sitting at $4^{\circ}$ overnight, ferritin crystals were harvested by centrifugation and washed with $5 \%$ cadmium sulfate. The crystals were redissolved, recrystallized three times, and finally dissolved in a minimal amount of $0.05 \mathrm{M}$ Tris-HCl, $\mathrm{pH} 7.7$, with $0.01 \mathrm{M}$ EDTA and chromatographed on Sephadex G-200 [11]. The ferritin fraction was collected, dialyzed against $0.25 \%$ sodium chloride with $0.02 \%$ sodium azide, and concentrated to approximately $15 \mathrm{mg} / \mathrm{ml}$. The ferritin contained $23 \%$ iron by weight.

\section{Rabbit Anti-human Ferritin Antibody}

Five milligrams of ferritin mixed with Freund's complete adjuvant were injected into the footpads of New Zealand White rabbits. The rabbits were bled and the antisera harvested 3 weeks later.

\section{Erythrocyte Incubation}

Human erythrocytes were collected in heparin, centrifuged, and washed three times with saline. Five to six milliliters of cells were then suspended in an equal volume of Krebs bicarbonate buffer $\mathrm{pH} 7.4$ and sufficient ${ }^{59} \mathrm{FeCl}_{3}$ was added to give a concentration of $2 \mu \mathrm{g}$ iron $/ \mathrm{ml}$ of incubation medium with a specific activity of $7.5 \mathrm{mCi} / \mu \mathrm{g}$ iron $\left(1.3 \times 10^{6} \mathrm{cpm} / \mathrm{ml}\right.$ incubation medium). After incubation for $2 \mathrm{hr}$ at $37^{\circ}$ in a $5 \% \mathrm{CO}_{2}$ and $95 \% \quad \mathrm{O}_{2}$ atmosphere, the cells were centrifuged, washed three times with saline, and hemolyzed with 2 volumes of distilled water. The hemolysate was centrifuged at $12,800 \times g$ for $30 \mathrm{~min}$. The supernatant was dialyzed overnight in preparation for chromatography on carboxymethyl cellulose, as described above, in order to obtain the non-hemoglobin protein, which was eluted from the column with the solvent front. This protein solution was then concentrated by ultrafiltration to a volume of $1-2 \mathrm{ml}$ for further analyses.

\section{Isotope Counting}

Radioactive counting was done in a well-type scintillation counter with a sodium iodicle crystal.

Protein determinations were done by the method of Lowry et al. [9], and iron determinations by the method of Trinder [13].

\section{Results}

The non-hemoglobin protein (NHP) obtained from 6 ml human erythrocytes incubated with ${ }^{59} \mathrm{Fe}$ as described contained between 2,000 and 4,000 cpm and approximately $40 \mathrm{mg}$ protein. Dialysis for $16 \mathrm{hr}$ against $0.01 \mathrm{M} \mathrm{NaPO}_{4}$ buffer, $\mathrm{pH} 6.6$, with $0.013 \mathrm{M}$ EDTA resulted in a loss of half of the counts. No further counts were lost on continued dialysis for up to $72 \mathrm{hr}$. If the $\mathrm{pH}$ of the dialysate were reduced to 4.0 , again no further counts were lost and only when the $\mathrm{pH}$ was reduced to 2.0 were the remaining counts dialyzable.

Heating the NHP to $80^{\circ}$ for 10 min resulted in a heavy precipitate. Approximately half of the ${ }^{59} \mathrm{Fe}$ counts present remained in the supernatant and these were nondialyzable at $\mathrm{pH} 6.6$.

When the NHP was chromatographed on carboxymethyl cellulose with acetate buffer at acid pH [14], the ${ }^{59} \mathrm{Fe}$ counts were eluted from the column with the same volume of the third buffer as was human ferritin chromatographed in the same manner. Approximately $1 / 3$ of the counts present in the NHP were recovered and the protein content was so low as to be unmeasurable even after concentration by ultrafiltration. Chromatography of this concentrated material on Sephadex G-200 revealed that all of the ${ }^{59} \mathrm{Fe}$ counts were eluted from the column immediately after the void volume. Human ferritin exhibited the same characteristics when chromatographed on Sephadex G-200.

That NHP which had been chromatographed on carboxymethyl cellulose and then Sephadex $\mathrm{G}$-200 was concentrated in $0.005 \mathrm{M}$ Tris- $\mathrm{HCl}, \mathrm{pH} 7.7$, with $0.01 \mathrm{M}$ EDTA to a volume of $1 \mathrm{ml}$. Then $0.1 \mathrm{ml}$ of the rabbit anti-human ferritin serum was added and the sample was incubated for $16 \mathrm{hr}$ at $37^{\circ}$. When the sample was centrifuged, $90 \%$ of the ${ }^{59} \mathrm{Fe}$ counts were in the precipitate with the remainder in the supernatant.

The results of electrophoresis on acrylamide gel of a sample of NHP prepared identically is shown in Figure 1 . When the gel is cut into $1-\mathrm{cm}$ sections and the ${ }^{59} \mathrm{Fe}$ content of each section is determined, the position of the counts in the gel corresponds to the position of human ferritin run on a similar gel at the same time.

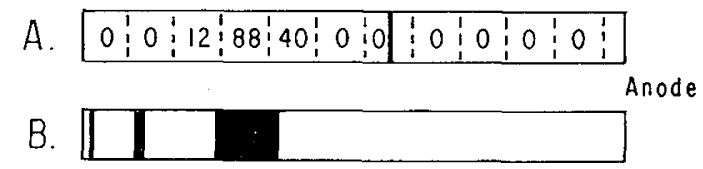

Fig. 1. Electrophoresis in a $5 \%$ acrylamicle gel with $0.05 \mathrm{M}$ glycine Tris-HCl buffer, pH 8.0, at 5 ma/gel. $A$ : non-hemoglobin protein of erythrocytes incubated with ${ }^{59} \mathrm{Fe}$ after chromatography on carboxymethyl cellulose at pH 4.8 and Sephadex G-200. The numbers refer to the ${ }^{59} \mathrm{Fe}$ counts in each segment of gel. $B$ : human ferritin run at the same time as $A$. The shaded portions of the gels represent stainable protein. 
The gel section that had a small amount of stainable protein had no ${ }^{59} \mathrm{Fe}$ counts.

When the ${ }^{59} \mathrm{Fe}$ was bound to human transferrin instead of being free in the incubation media, no counts were found in the NHP when erythrocytes from the peripheral blood of normal individuals were used. However, when reticulocyte rich peripheral blood from a patient with hereditary spherocytosis was used with transferrin bound $59 \mathrm{Fe}$, the NHP contained a large number of counts.

\section{Discussion}

Normal, mature, human erythrocytes were found to contain a protein capable of binding iron firmly. This protein proved to be ferritin, as evidenced by its migration on acrylamide gel electrophoresis, its behavior when chromatographed on carboxymethyl cellulose and Sephadex G-200, its heat stability and failure to dissociate its iron at a $\mathrm{pH}$ of 4.0 , and its precipitation by rabbit anti-human ferritin antibody. That it was present in mature erythrocytes and not just in the few reticulocytes present in normal peripheral blood was evidenced by the fact that if the iron were transferrin bound, instead of being free in the media, no measurable uptake into ferritin was found when erythrocytes from normal blood were used. However, when reticulocyte-rich blood was used, uptake from transferrinbound iron into ferritin was observed.

Ferritin is known to be present in erythroblasts and reticulocytes [2], but this is the first demonstration of ferritin in the soluble portion of normal mature human erythrocytes. Although there is one report of ferritin in the membranes of rabbit erythrocytes [8], and ferritin was said to contaminate catalase preparations from horse erythrocytes [1], the most compelling evidence reported previously indicates that ferritin is not present in mature erythrocytes. Electron microscopic studies have shown it be be absent [2]; if ${ }^{59} \mathrm{Fe}$ is injected into rats or a splenectomized human, labeled ferritin is found in the developing erythroblasts, but not in peripheral blood erythrocytes [14]; ferritin has been shown to be transported out of guinea pig erythroblasts [12] and swine siderocytes [6]; the spleen removes siderophilic granules from erythrocytes in humans [5]. However, these studies which indicate that ferritin is not present in erythrocytes and suggest the mechanisms for its removal as the cell matures require the presence of iron in the molecule. In the present study, the ability of the protein to bind iron allowed for its identification; therefore, the ferritin in the erythrocyte is not fully saturated with iron and may be mostly apoferritin. This could explain the apparent discrepancy in these data. The other possible explanation is that the amount of ferritin present is so small that it is not apparent by the other methods used to identify it.

If erythrocyte ferritin is mostly saturated with iron and is present normally in small amounts, this would fit best with the available evidence that ferritin iron is not available for hemoglobin synthesis $[11,14]$. However, this evidence was obtained using relatively short term experiments. Over a longer period of time in vivo or when iron is less readily available, ferritin iron might be utilized for hemoglobin synthesis. If erythrocyte ferritin were unsaturated and occurred mainly as apoferritin, this would support the hypothesis that the ferritin iron was available for hemoglobin synthesis. In order to determine this, current investigation involves quantitation of erythrocyte ferritin and determination of its iron content.

\section{References and Notes}

1. Agner, K.: Erythrocyte catalase. Arkiv. Kemi, $13 d, 17 B(9): 1$ (1943).

2. Bessis, M. C., AND Breton-Gorius, J.: Iron metabolism in the bone marrow as seen by electron microscopy: A critical review. Blood, 19: 635 (1962).

3. Bothwell, T. H., And Frnch, C. A.: Iron Metabolism, p. 272 (Little, Brown and Company, Boston, I962).

4. Chernoff, A. I., Petrrt, N., and Northrop, J.: The amino acid composition of hemoglobin. V. The preparation of purified hemoglobin fractions by chromatography on cellulose exchangers and their identification by starch gel electrophoresis using Tris-borate-EDTA buffer. Blood, 45: 646 (1965).

5. Crosby, W. H.: Siderocytes and the spleen. Blood, 12: 165 (1956).

6. Deiss, A., and Cartwright, G. E.: Ferritin metabolism in reticulated siderocytes. J. Clin. Invest., 49: 517 (1970).

7. Drysdale, J. W., ANd Munro, H. N.: Small-scale isolation of ferritin for the assay of the incorporation of ${ }^{14} \mathrm{C}$-labelled amino acids. Biochem. J., 95: 851 (1965).

8. Falbe-Hensen, I., and Lothe, K.: In vivo incorporation of ${ }^{59} \mathrm{Fe}$ into non-heme iron and hemoglobin of red blood cells. Acta Physiol. Scand., 54: 97 (1962).

9. Lowry, O. H., Rosebrough, N. J., Farr, A. L., and Randall, R. J.: Protein measurement with Folin phenol reagent. J. Biol. Chem., 193: 265 (1951).

10. Nerenberg, S. T.: Electrophoresis (F. A. Davis Co., Philadelphia, 1966).

11. Primosigh, J. V., and Thomas, E. D.: Studies on the partition of iron in bone marrow cells. J. Clin. Invest., 47: 1473 (1968).

12. TANAKA, Y.: Bi-directional transport of ferritin in guinea pig erythroblasts in vitro. Blcod, 35: 793 (1970). 
13. Trinder, P.: The improved determination of iron in serum. J. Clin. Pathol., 9: 170 (1956).

14. Zail, S. S., Charlton, R. W., Torrance, J. D., and Bothwell, T. H.: Studies on the formation of ferritin in red cell precursors. J. Clin. Invest., 43: 670 (1964).

15. I wish to acknowlcdge the expert technical assistance of Miss Jenny Hill.
16. This work was supported in part by Public Health Service Grant no. S-T-12 CA08053.

17. Requests for reprints should be addressed to: F. Stanley PorTer, M.D., Professor of Pediatrics, Pediatric Hematology, Duke University School of Medicine (Medical Center), Durham, N. C. 27710 (USA).

18. Accepted for publication July 20, 1973. 